\title{
Foundational Leadership Theory: A New Ethical Approach to Reducing Knowledge-Hiding Practices Among Employees
}

\author{
LaJuan Perronoski Fuller ${ }^{1}$ \\ ${ }^{1}$ Glenn R. Jones College of Business, Trident University International, Cypress, CA, USA \\ Correspondence: LaJuan Perronoski Fuller, Ph.D., Trident University International, Cypress, CA, USA.
}

Received: July 7, 2021

Accepted: July 27, $2021 \quad$ Available online: August 4, 2021

doi:10.11114/ijsss.v9i5.5286

URL: https://doi.org/10.11114/ijsss.v9i5.5286

\begin{abstract}
Knowledge hiding is a destructive behavior that degrades organizational success. Knowledge hiding is the intentional withholding of information from another employee. It has been reported that $76 \%$ of U.S. employees hide knowledge from each other. The displaced aggression theory suggests that employees are more likely to hide knowledge from others in the presence of mistreatment by a leader. Therefore, there was a need to investigate new ethical theories that have been shown to influence organizational commitment and potentially decrease knowledge-hiding practices among employees. This research used foundational leadership theory (FLT) developed by Fuller in 2021 to examine the overall influence on knowledge hiding. The sample consisted of 306 full-time employees across various industries throughout the United States. The results indicated that FLT had a significant negative relationship (-0.64); regression analysis indicated that, as FLT increased, knowledge hiding decreased by 0.57 . Therefore, leadership training programs that teach ethical leaders based on integrity, assurance, and pragmatism will likely reduce knowledge hiding tactics among employees and create a strategic advantage among competitors.
\end{abstract}

Keywords: ethical leadership, knowledge hiding, organizational leadership, ethical theory

\section{Introduction}

Knowledge hiding is an employee's attempt to intentionally withhold or conceal information (Connelly et al., 2012). Employees hide knowledge by pretending not to know (Connelly \& Zweig, 2015) or blaming others for lack of information (Arain et al., 2020). Knowledge hiding has become a destructive behavior that hinders knowledge transfer (Offergelt et al., 2019; Schyns \& Schilling, 2013). This can present challenges for leaders who rely on knowledge sharing and transfer to create strategic advantages over competitors.

Displaced aggression theory (DAT) suggests that employees may hide knowledge when they are not treated well by leaders (Mitchell \& Ambrose, 2007; Skarliciki \& Folger, 1997). Wang et al. (2019) used DAT and confirmed that employees were more likely to have destructive behaviors toward each other rather than their leaders. This is primarily due to leaders having authority over employee rewards and promotions. This explains why $76 \%$ of sampled U.S. employees admit to hiding knowledge from each other (Connelly et al., 2012) and is estimated to cost Fortune 500 companies approximately \$31.5 billion in revenue (Babcock, 2004; Chenghao et al., 2020).

Gaps in the literature exist concerning the association between leadership variables and knowledge hiding (Černe et al., 2014; Tang et al., 2015). Additionally, theoretical and empirical methods for studying knowledge hiding remain underdeveloped and untested (Men et al., 2018). Comparatively, the literature suggests that ethical leadership can reduce knowledge hiding (Khalid et al., 2018; Ladan et al., 2017; Lee et al., 2018; Zhao \& Xia, 2019). This confirms the need to investigate the affect concerning ethical leadership and knowledge hiding.

The purpose of this study is to better understand foundational leadership theory (FLT) and reducing knowledge hiding among employees. FLT builds on the ethic position theory and suggests that employees perceive integrity, assurance, and pragmatism as ethical leadership attributes (Fuller, 2021a). Because knowledge hiding is inimical to organizational success (Connelly et al., 2017), this study aims to contribute to the literature by providing other methods to assess ethics and reducing knowledge hiding practices (Offergelt et al., 2019).

Ethical leaders create organizational commitment (Mackey et al., 2017), which predicts knowledge-sharing behaviors (Cerne et al., 2014; Peng \& Wei, 2018; Skerlavaj et al., 2018). Comparatively, FLT's integrity, assurance, and 
pragmatism have been validated as an ethical leadership measurement and predicted organizational commitment (Fuller, 2021a). FLT should provide a suitable ethical model and assessment (Lee et al., 2018) to enhance our understanding of methods to reduce knowledge hiding (Tang et al., 2015). Therefore, if employees perceive integrity, assurance, and pragmatism as ethical leadership attributes, then those employees will be less likely to hide knowledge from each other.

Research Question: Do employees who perceive leadership as having integrity, assurance, and pragmatism less likely to hide knowledge from each other?

\section{Literature Review}

Knowledge hiding is an intentional attempt to conceal knowledge requested by co-workers based on the behaviors: claiming not to have the knowledge ("playing dumb"), evasive hiding, and rationalized hiding (Connelly et al., 2012). Playing dumb requires that the knowledge hider pretend not to understand questions or show a lack of interest in helping others. Evasive hiding is a deceptive tactic by which knowledge hiders provide incorrect information to the requester (Connelly et al., 2012). In rationalized hiding, the knowledge hiders blame others for justifying not providing relevant knowledge (Connelly et al., 2012). Some employees may consider rationalized hiding as a nondeceptive tactic (Connelly \& Zweig, 2015).

Connelly et al. (2012) confirmed that knowledge hiding is multidimensionally noted that each dimension may be related to antecedents and mediators. Thus, rationalized hiding may be a minor infraction, such as giving misinformation about a meeting, or a significant infraction, such as hiding major strategies (Serenko \& Bontis, 2016). Although employees may consider rationalized knowledge hiding to be purposeful (Connelly et al., 2012), it is less likely that ethical leaders will have employees willing to engage in this tactic. This suggests that knowledge hiders may not directly intend to harm the organization or its members.

\subsection{Ethical Leadership and Knowledge Hiding}

Ethical leadership encompasses two crucial dimensions. First, the moral dimension consists of personal traits and characteristics such as integrity, honesty, and trustworthiness (Brown et al., 2005). The other dimension is the moral manager, who punishes unethical behaviors and encourages ethical behaviors (Brown \& Trevino, 2006). According to Bouckenooghe et al. (2015), these proactive measures hold followers responsible for acceptable conduct while treating employees fairly. This supports social learning theory (Bandura, 1977), which suggests that ethical leadership may influence employee behaviors but not measure other facets of the leader-follower relationship (Zhang et al., 2012).

Ethical leadership has mediating roles on follower outcomes. For example, Zhu et al. (2013) used affective trust to assess social exchanges between leaders and followers. Trust defined the high-quality relationship but may have obstructed consideration of other dimensions or facets that foster leader-follower exchanges (Zhang et al., 2012). Edmondson (1999) suggested that mutual respect through trust may influence an employee's willingness to share knowledge. Fuller (2021b) used Lewicki and Bunker's (1996) knowledge-based trust (KBT) theory and reported that trust predicted employees' willingness to share tacit knowledge. Fuller (2021b) did not investigate the effect of ethical leadership on employee willingness to share knowledge. Therefore, this study considered ethical leadership attributes built on integrity, assurance, and pragmatism as a trust mechanism.

Ethical leaders do not compromise integrity; they strive to make fair decisions in the best interest of employees and the organization (Den Hartog, 2015; Usman \& Hameed, 2017). Abdullah et al. (2019) used social learning theory (SLT) and social exchange theory (SET) to assess how ethical leadership discourages knowledge-hiding behavior. They concluded that attributes such as integrity decreased deceptive behaviors such as knowledge hiding. FLT contributes to this research by introducing ethical leadership built on assurance and pragmatism in addition to integrity.

Tang et al. (2015) were among the first researchers to fully explore the relationship between ethical leadership and knowledge hiding in the workplace. However, that study observed university students rather than employees. SLT has shown promise in assessing the link between ethical leadership and knowledge hiding (Khalid et al., 2018). However, Sturm (2017) argued that moral attractiveness and reflectiveness could decrease unethical decisions. Other ethical theories cannot be ruled out in attempts to gain insight into possible links between ethical leadership and knowledge-hiding behaviors (Huo et al., 2016). FLT considers moral attractiveness and reflection using an inward/outward approach based on integrity, assurance, and pragmatism to account for perceived unethical leadership behavior (Fuller, 2021a).

\subsection{Displaced Aggression Theory and Knowledge Hiding}

DAT suggests that employees who feel victimized by supervisory mistreatment do not show aggression toward their supervisor. Instead, their negative feelings are directed toward convenient targets, such as other employees (Skarlicki \& Folger, 1997). Mitchell and Ambrose (2007) confirmed Skarlicki and Folger's (1997) results and suggested that employees who feel mistreated seek revenge on leaders by hiding knowledge from co-workers. Because leaders 
exercise authority over rewards and promotions, employees are less likely to display negative behaviors toward those leaders (Wang et al., 2019). For strategic reasons, it is difficult to eradicate perceived leadership abuse (Khan et al., 2019). However, FLT accounts for social norms that may provide leaders with a process to account for decisions that may be perceived as unethical or abusive to employees (Fuller, 2021a).

Kahlid et al. (2018) and Islam et al. (2021) investigated the role of abusive leadership to explain knowledge-hiding behaviors by employees. Employees who perceived their knowledge as valuable (Kim et al., 2016) were more likely to hide knowledge from other employees (Islam et al., 2021; Kahlid et al., 2018). These results aligned with uncertainty management theory (van den Bos \& Lind, 2002), suggesting that the perception of injustice results in action to regain lost control. Therefore, knowledge-hiding behaviors may become a threat to organization objectives. However, Tepper (2007) suggested that knowledge-hiding behaviors may be controlled by reducing abusive organizational leadership. Previous studies confirmed the relationship between abusive supervision and knowledge sharing (Kim et al., 2016; Wu \& Lee, 2016, 2017). However, FLT may further explain DAT by providing insight into positive leadership behaviors that reduce knowledge-hiding tactics by employees.

\subsection{Foundational Leadership Theory and Knowledge Hiding}

FLT consists of foundational leadership-integrity (FLI), foundational leadership-assurance (FLA), and foundational leadership-pragmatism (FLP). First, FLI was used as the foundation of organizational justice and fairness. McGregor (1960) reported that fairness is related to ethical leadership. Leaders with integrity were perceived as acting in the best interest of the organization (Brown et al., 2005), being honest and fair (Jordan et al., 2017), and enhancing follower perception (Ming et al., 2020). This suggests that FLI should provide insight into the link between ethical leadership and "rationalized' knowledge hiding in which others are blamed for lack of information.

FLA is the second stage of FLT and accounts for moral sensitivity. Leaders' moral sensitivity has been shown to influence employee uncertainty. Brown et al. (2005) found that ethical decision-making contributed to employees' overall effectiveness and efficiency. FLA integrated employee perception of ethical leadership based on decisions that promote stress, anxiety, and uncertainty. FLA was shown to influence organizational commitment (Fuller, 2021a), which has been shown to predict knowledge-sharing behaviors (Cerne et al., 2014; Peng and Wei, 2018; Skerlavaj et al., 2018). Therefore, FLA may establish ethical leadership standards that reduce employee knowledge-hiding behaviors.

FLP builds on SET, which labels pragmatism as a fundamental approach to leadership decision-making (Homans, 1974). Because pragmatism appears most in organizational routines (Winter, 2013), employees who perceive leaders as pragmatic are likely to accept their decisions to help them achieve personal and professional goals (Jensen \& Sandstrom, 2013). Based on the SET approach, FLP accounts for pragmatic forms of ethical leadership to improve employee dedication to the organization (Anderson \& Sun, 2017). This explains why FLT predicted organizational commitment (Fuller, 2021a) and may contribute to understanding the influence of DAT on employee-to-employee destructive behaviors reflected in knowledge hiding practices (see Figure 1).

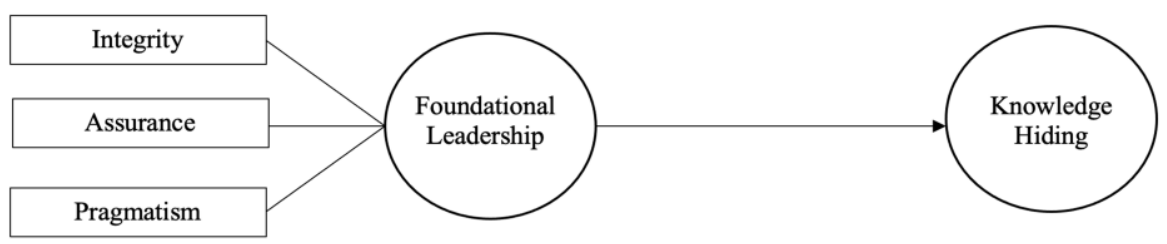

Figure 1. Foundational Leadership and Knowledge Hiding Conceptual Model

Ethics position theory (EPT; Forsyth, 1980, 1992) posits that moral actions and evaluations are outward expressions of a person's ethical position. EPT is applied to explain behaviors and actions in specific situations and ethical scenarios based on idealism and relativism decision-makers. Decision-makers who are high in idealism show concern for the welfare of others (Forsyth, 1992). Relativism measures the degree to which the decision-maker complies with rules and regulations in the workplace (Forsyth, 1992). Therefore, Fuller (2021a) confirmed that employees who perceived leaders as having foundational leadership attributes (integrity, assurance, and pragmatism) would predict organizational commitment. Comparatively, this researcher proposed the following hypotheses on FLT and reducing knowledge hiding tactics between employees.

$\mathrm{H}_{0}$ : FLT has no relationship with knowledge-hiding tactics. 
$\mathrm{H}_{1}$ : FLT has a significant negative relationship with knowledge-hiding tactics.

\section{Method}

This study used a cross-sectional, quantitative study design. The research followed general regression analysis procedures to explain the association and relationship between the independent variable (IV) FLT and dependent variable (DV) knowledge hiding. Cronbach's alpha was used to measure the scale reliability of the Likert-type scale. Pearson's correlation was used to measure relationships between the IV and DV. The results were tested for assumptions of normality, homoscedasticity, outliers, and regression paths. However, since there is only one predictor variable, multicollinearity did not apply, and variance inflation factors were not addressed in this study. The research followed general procedures for Pearson correlation and regression analysis. Linear regression analysis was used to measure the positive or negative strength between the IV and DV. Linear regression confirmed this measurement model.

Only full-time employees were recruited to streamline the process and to minimize erroneous data. Part-time or seasonal employees or self-employed persons did not participate. Full-time employee work data were retrieved from the U.S. Department of Labor, current as of April 2020. The U.S. workforce was estimated at approximately 136 million (not including seasonal or holiday employees). This study used a confidence interval (CI) of $95 \%$ with an acceptable margin of error of $4 \%$ to $6 \%$. The minimum acceptable sample size was 270 ; the aim was 300 participants to meet correlation and regression analysis criteria. Gender differences can affect ethical judgment, decisions, and behavior (Marcus \& Schuler, 2004) and can potentially influence knowledge hiding (Peng, 2013). Previous research has shown that gender did not have significant correlations with outcome variables. Therefore, this study replicated Peng's (2013) control variable to provide insight into the relationship between gender and knowledge hiding.

The survey was sent via SurveyMonkey ${ }^{\mathrm{TM}}$; each participant was randomly selected and required to read instructions before responding to the survey. Persons who selected "I do not agree" were not given access to the survey and were diverted to a screen stating, "Thank you for your participation." Persons who agreed to participate were given access to the survey after signing informed consent. In this cross-sectional quantitative study, the researcher collected and analyzed data from 321 participants to measure the possible influence of FLT on knowledge hiding. However, 15 response sets were deleted due to incomplete or erroneous responses. Therefore, the IV FLT and DV knowledge hiding measures were based on 306 completed surveys from full-time employees in the United States. A 15-item scale measured the IV by Fuller (2021a) and a 12-item scale by Connelly et al. (2012).

FLT measures perceived integrity, assurance, and pragmatism for ethical decision-making. Therefore, it was hypothesized that ethical decisions grounded in FLT would significantly predict organizational commitment and reduce knowledge-hiding behaviors by employees. FLT consisted of a 15-item scale developed and validated by Fuller (2021a), using a 7-point Likert-type measurement scale (example, "I trust leadership decisions that promote job security"). Each response was based on a 7-point Likert-type scale $(1=$ strongly disagree to $7=$ strongly agree $)$. Knowledge hiding was measured based on a 12-item scale developed and validated by Connelly et al. (2012; example: "I agreed to help him/her but instead gave him/her information different from what s/he wanted"). Each response was based on a 7-point Likert-type scale $(1=$ not at all, $7=$ to a very great extent $)$. Each response was given under anonymous conditions; no personally identifiable information was collected.

\section{Results}

The most frequently observed age category was 45 to $60(n=96,31 \%)$. The most frequently observed category of gender was female $(n=192,63 \%)$. Frequency and percentages are listed in Table 1.

Table 1. Participant demographics $(N=306)$

\begin{tabular}{lcc}
\hline Variable & $n$ & $\%$ \\
\hline Age & & \\
$18-29$ & 75 & 24.51 \\
$30-44$ & 72 & 23.53 \\
$45-60$ & 96 & 31.37 \\
$60>$ & 63 & 20.59 \\
Gender & & \\
Male & 114 & 37.25 \\
Female & 192 & 62.75 \\
\hline
\end{tabular}


Summary statistics were calculated for FLQ1, FLQ2, FLQ3, FLQ4, FLQ5, FLQ6, FLQ7, FLQ8, FLQ9, FLQ10, FLQ11, FLQ12, FLQ13, FLQ14, FLQ15, KHQ1, KHQ2, KHQ3, KHQ4, KHQ5, KHQ6, KHQ7, KHQ8, KHQ9, KHQ10, KHQ11, and KHQ12 (Table 2).

Table 2. Summary statistics for interval and ratio variables

\begin{tabular}{|c|c|c|c|c|c|c|}
\hline Variable & $M$ & $S D$ & $n$ & $\mathrm{SE}_{\mathrm{M}}$ & Min & Max \\
\hline FLQ1 & 6.12 & 1.55 & 306 & 0.09 & 1.00 & 7.00 \\
\hline FLQ2 & 6.14 & 1.56 & 306 & 0.09 & 1.00 & 7.00 \\
\hline FLQ3 & 6.15 & 1.52 & 306 & 0.09 & 1.00 & 7.00 \\
\hline FLQ4 & 6.00 & 1.43 & 306 & 0.08 & 1.00 & 7.00 \\
\hline FLQ5 & 6.08 & 1.33 & 306 & 0.08 & 1.00 & 7.00 \\
\hline FLQ6 & 5.95 & 1.58 & 306 & 0.09 & 1.00 & 7.00 \\
\hline FLQ7 & 5.97 & 1.46 & 306 & 0.08 & 1.00 & 7.00 \\
\hline FLQ8 & 5.65 & 1.39 & 306 & 0.08 & 1.00 & 7.00 \\
\hline FLQ9 & 6.07 & 1.31 & 306 & 0.07 & 1.00 & 7.00 \\
\hline FLQ10 & 5.74 & 1.36 & 306 & 0.08 & 1.00 & 7.00 \\
\hline FLQ11 & 5.73 & 1.55 & 306 & 0.09 & 1.00 & 7.00 \\
\hline FLO12 & 5.49 & 1.36 & 306 & 0.08 & 1.00 & 7.00 \\
\hline FLQ13 & 5.58 & 1.53 & 306 & 0.09 & 1.00 & 7.00 \\
\hline FLQ14 & 5.75 & 1.38 & 306 & 0.08 & 1.00 & 7.00 \\
\hline FLQ15 & 5.72 & 1.30 & 306 & 0.07 & 1.00 & 7.00 \\
\hline KHQ1 & 2.38 & 1.76 & 306 & 0.10 & 1.00 & 7.00 \\
\hline KHQ2 & 2.20 & 1.70 & 306 & 0.10 & 1.00 & 7.00 \\
\hline KHO3 & 2.14 & 1.71 & 306 & 0.10 & 1.00 & 7.00 \\
\hline KHO4 & 2.03 & 1.57 & 306 & 0.09 & 1.00 & 7.00 \\
\hline KHQ5 & 2.01 & 1.66 & 306 & 0.09 & 1.00 & 7.00 \\
\hline KHQ6 & 2.08 & 1.63 & 306 & 0.09 & 1.00 & 7.00 \\
\hline KHQ7 & 2.04 & 1.55 & 306 & 0.09 & 1.00 & 7.00 \\
\hline KHQ8 & 2.18 & 1.46 & 306 & 0.08 & 1.00 & 7.00 \\
\hline KHQ9 & 2.20 & 1.60 & 306 & 0.09 & 1.00 & 7.00 \\
\hline KHQ10 & 2.83 & 1.79 & 306 & 0.10 & 1.00 & 7.00 \\
\hline KHQ11 & 2.42 & 1.74 & 306 & 0.10 & 1.00 & 7.00 \\
\hline KHQ12 & 1.94 & 1.46 & 306 & 0.08 & 1.00 & 7.00 \\
\hline
\end{tabular}

A Cronbach's alpha coefficient was provided for the Knowledge Hiding scale, consisting of KHQ1, KHQ2, KHQ3, KHQ4, KHQ5, KHQ6, KHQ7, KHQ8, KHQ9, KHQ10, KHQ11, KHQ12, and Foundational Leadership scale, consisting of FLQ1, FLQ2, FLQ3, FLQ4, FLQ5, FLQ6, FLQ7, FLQ8, FLQ9, FLQ10, FLQ11, FLQ12, FLQ13, FLQ14, and FLQ15. The Cronbach's alpha coefficient was calculated using guidelines suggested by George and Mallery (2018), where $>9=$ excellent, $>.8=$ good, $>.7=$ acceptable, $>.6=$ questionable, $>.5=$ poor, and $\leq .5=$ unacceptable. The items for Knowledge Hiding had a Cronbach's alpha coefficient of .93, and FLT had a Cronbach's alpha of .95, indicating excellent reliability. Table 3 presents the results of the reliability analysis.

Table 3. Reliability coefficients for knowledge hiding and foundational leadership theory

\begin{tabular}{lrrrr}
\hline Scale & No. of Items & $\alpha$ & Lower Bound & Upper Bound \\
\hline Knowledge Hiding & 12 & 0.93 & 0.92 & 0.94 \\
\hline Foundational Leadership Theory & 15 & 0.95 & 0.94 & 0.96 \\
\hline
\end{tabular}

Note. The lower and upper bounds of Cronbach's $\alpha$ were calculated using a 95\% confidence interval.

A Pearson correlation analysis was conducted between Foundational Leadership and Knowledge Hiding. The result of the correlation was examined based on an alpha value of .05. A significant negative correlation was observed between 
Foundational Leadership and Knowledge Hiding ( $\mathrm{RP}=-0.64, p<.001,95 \% \mathrm{CI}[-0.70,-0.56])$. The correlation coefficient between Foundational Leadership and Knowledge Hiding was -.64, indicating a large effect size based on Cohen's (1988) standard where coefficients between .10 and .29 represent small effect sizes, coefficients between .30 and .49 represent moderate effect sizes, and coefficients above .50 indicate large effect sizes. This correlation indicated that, as Foundational Leadership increased, Knowledge Hiding tended to decrease. Table 4 presents the results of the correlation.

Table 4. Pearson correlation results between foundational leadership and knowledge hiding $(N=306)$

\begin{tabular}{lrrrr}
\hline Combination & R.P. & $95 \%$ CI & $p$ \\
\hline FLT-Knowledge Hiding & -0.64 & {$[-0.70,-0.56]$} & $<.001$ \\
\hline
\end{tabular}

A linear regression analysis assessed whether Foundational Leadership significantly predicted Knowledge Hiding. The linear regression model results were significant, $F(1,304)=206.39, p<.001, R^{2}=.40$, indicating that Foundational Leadership explained approximately $40 \%$ of the variance in Knowledge Hiding. Therefore, Foundational Leadership significantly predicted Knowledge Hiding, $B=-0.57, t(304)=-14.37, p<.001$. This indicated that, on average, a one-unit increase in Foundational Leadership was associated with a 0.57 unit decrease in Knowledge Hiding. Table 5 summarizes the regression model.

Table 5. Results of linear regression analysis for foundational leadership predicting knowledge hiding

\begin{tabular}{lrrrrrr}
\hline Variable & $\mathrm{B}$ & S.E. & $95 \%$ CI & $\beta$ & $\mathrm{t}$ & $\mathrm{p}$ \\
\hline (Intercept) & 76.35 & 3.53 & {$[69.40,83.31]$} & 0.00 & 21.60 & $<.001$ \\
FLT & -0.57 & 0.04 & {$[-0.64,-0.49]$} & -0.64 & -14.37 & $<.001$ \\
\hline Note. $F(1,304)=206.39, p<.001, R^{2}=.40$ & & & &
\end{tabular}

Analysis of variance (ANOVA) explored the potentially significant differences in Knowledge Hiding by gender, alpha $<.05$. The results were not significant, $F(1,304)=0.90, p=.344$, indicating that differences in Knowledge Hiding were similar between genders $F(1,304)=0.90, p=.344$. Means and standard deviations are listed below in Table 7 .

Table 6. Results of analysis of variance for knowledge hiding by gender

\begin{tabular}{lrrrrr}
\hline Term & S.S. & $d f$ & $F$ & $p$ & $\eta_{\mathrm{p}}^{2}$ \\
\hline Gender & 193.69 & 1 & 0.90 & .344 & 0.00 \\
Residuals & 65437.75 & 304 & & & \\
\hline
\end{tabular}

Table 7. Means, standard deviations, and sample size for knowledge hiding by gender

\begin{tabular}{lrrr}
\hline Combination & $M$ & $S D$ & $n$ \\
\hline Male & 27.47 & 15.03 & 114 \\
Female & 25.83 & 14.46 & 192 \\
\hline
\end{tabular}

\section{Discussion}

This research examined the influence of foundational leadership on knowledge hiding. There are a few theoretical contributions based on Pearson correlation and regression analysis output. First, the findings confirmed that ethical leaders are less likely to have employees who engage in knowledge-hiding tactics (Connelly et al., 2012; Offergelt et al., 2019). This is consistent and supports the need to advance the literature on ethical leadership and knowledge hiding (Cerne et al., 2014; Tang et al., 2015). Furthermore, FLT revealed a significant negative correlation with knowledge hiding. Based on the linear regression results, employees are less likely to engage in these destructive behaviors for leaders who practice integrity, assurance, and pragmatism. This validated the ethical attributes of FLT as a reliable method for reducing knowledge-hiding behaviors. 
Next, previous research revealed that integrity, assurance, and pragmatism measured ethical leadership, which predicted organizational commitment (Fuller, 2021a). Furthermore, it was hypothesized that FLT would reduce knowledge-hiding behaviors. The findings are consistent with previous theoretical contributions that affective commitment may reduce knowledge hiding (Peng et al., 2013; Peng and Wei, 2018; Skerlavaj et al., 2018). This observation is based on the significant negative effect size of -.64 according to Cohen's (1988) standard. Regression analysis determined that, as FLT increased, knowledge hiding decreased by 0.57 , regardless of participant gender differences.

There are a few practical implications in the research. The hypothesis that FLT would decrease knowledge hiding behaviors among employees was accepted. Therefore, leaders, managers, and supervisors should consider using integrity, assurance, and pragmatism to increase organizational commitment (Fuller, 2021a) and reduce knowledge-hiding behaviors (Koay et al., 2020; Ladan et al., 2017). Next, the findings contributed to developing new theoretical and empirical ethical methods (Connelly et al., 2017; Men et al., 2018). This study further explains DAT and reveals that integrity, assurance, and pragmatism reduce destructive behaviors such as knowledge hiding (Wang et al., 2019). Therefore, this study added to the present literature by employing FLT as a practical method for reducing knowledge-hiding tactics (Offergelt et al., 2019).

This research has limitations based on using a cross-sectional study method. Relationships between FLT and knowledge hiding may change over time. The 306 participants in this study might have yielded different ANOVA results if race, sexual orientation, or time on the job had been used as controls. There were possible sample biases in the study. First, the research could not measure the entire population; data were collected from a sample consisting of 306 full-time employees to reduce this bias. Participants may have rushed to complete each question or not answered them to the best of their knowledge. To mitigate this possibility, the survey contained only 29 one-sentence items to address all variables and demographics in the study. Each item was derived from previously validated and accepted studies to decrease survey item bias.

Further research is needed to determine whether leadership styles mediate or moderate the negative relationship between FLT and knowledge hiding. Further studies on leadership styles such as transformational and transaction may improve the literature on the predictive power of FLT on knowledge-hiding behaviors. Participant gender was examined, and the results showed no significant effect. However, future research should include other demographic categories. This would add to the literature and inform leaders and managers about gender differences in knowledge-hiding concepts.

\section{Conclusion}

There was a need to investigate ethical leadership styles to advance research on knowledge hiding (Cerne et al., 2014; Tang et al., 2015). Research has shown that ethical leaders influence affective commitment (Berthelsen et al., 2018; Peng \& Wei, 2018), which improves positive knowledge-sharing behaviors among employees (Skerlavaj et al., 2018). This study confirmed that integrity, assurance, and pragmatism measured ethical leadership and reduced knowledge hiding among employees. Previous literature suggested that ethics can be taught (Jones, 2009; Lau, 2010) and reduces knowledge-hiding behaviors (Khalid et al., 2018; Ladan et al., 2017; Zhao \& Xia, 2019). Therefore, it may be beneficial to develop leadership training based on foundational leadership's integrity, assurance, and pragmatism to improve organizational commitment (Fuller, 2021a), reduce destructive knowledge hiding that hinders knowledge transfer (Offergelt et al., 2019), and create strategic advantages over competitors.

\section{References}

Abdullah, M. I., Dechun, H., Ali, M., \& Usman, M. (2019). Ethical leadership and knowledge hiding: A moderated mediation model of relational social capital, and instrumental thinking. Frontiers in Psychology, 10, 2403-2403. https://doi.org/10.3389/fpsyg.2019.02403

Anderson, M., \& Sun, P. (2017). Reviewing leadership styles: Overlaps and the need for a new full-range theory. International Journal of Management Reviews, 19, 76-96. https://doi.org/10.1111/ijmr.12082

Arain, G., Bhatti, Z. A., Ashraf, N., \& Fang, Y-H. (2020). Top-down knowledge hiding in organizations: An empirical study of the consequences of supervisor knowledge hiding among local and foreign workers in the Middle East. Journal of Business Ethics, 164(3), 611-625. https://doi.org/10.1007/s10551-018-4056-2

Babcock, P. (2004). Shedding light on knowledge management. H.R. Magazine 49, 46-50.

Bandura, A. (1977). Social learning theory. Prentice-Hall.

Berthelsen, H., Hakanen, J., \& Westerlund, H. (2018). Copenhagen Psychosocial Questionnaire. A validation study using job demand-resource model. PLoS One, 13(4), e0196450. https://doi.org/10.1371/journal.pone.0196450

Bouckenooghe, D., Zafar, A., \& Raja, U. (2015). How ethical leadership shapes employees' job performance: The mediating roles of goal congruence and psychological capital. Journal of Business Ethics, 129(2), 251-264. 
https://psycnet.apa.org/doi/10.1007/s10551-014-2162-3

Brown, M. E., \& Treviño, L. K. (2006). Ethical leadership: A review and future directions. Leadership Quarterly, 17, 595-616. https://doi.org/doi: 10.1016/j.leaqua.2006.10.004

Brown, M. E., Treviño, L. K., \& Harrison, D. A. (2005). Ethical leadership: A social learning perspective for construct development and testing. Organizational Behavior and Human Decision Processes, 97(2), 117-134. https://doi.org/10.1016/j.obhdp.2005.03.002

Cerne, M., Nestad, C. G. L., \& Skervalaj, M. (2014). What goes around comes around: Knowledge hiding perceived motivational climate and creativity. Academy of Management Journal, 57, 172-192. https://doi.org/10.5465/amj.2012.0122

Chenghao, M., Fong Patrick, S. W., Weiwei, H., Jing, Z., Ruiqian, J., \& Jinlian, L. (2020). Ethical leadership and knowledge hiding: A moderated mediation model of psychological safety and mastery climate. Journal of Business Ethics, 166(3), 461-472. https://doi.org/10.1007/s10551-018-4027-7

Cohen, J. (1988). Statistical power analysis for the behavior sciences (2nd ed.). West Publishing Company.

Connelly, C. E., \& Zweig, D. (2015). How perpetrators and targets construe knowledge hiding in organizations. European Journal of Work and Organizational Psychology, 24(3), 479-489. https://doi.org/10.1080/1359432X.2014.931325

Connelly, C. E., Dysvik, A., Škerlavaj, M., \& Cerne, M. (2017). Understanding knowledge hiding in organizations. http://onlinelibrary.wiley.com/store/10.1002/(ISSN)1099-1379/asset/homepages/

Connelly, C. E., Zweig, D., Webster, J., \& Trougakos, J. P. (2012). Knowledge hiding in organizations. Journal of Organizational Behavior, 33, 64-88. https://doi.org/10.1002/job.737

Den Hartog, D. N. (2015). Ethical leadership. Annual Review of Organizational Psychology and Organizational Behavior, 2, 409-434. https://doi.org/10.1146/annurev-orgpsych-032414-111237

Edmondson, A. (1999). Psychological safety and learning behavior in work teams. Administrative Science Quarterly, 44(2), 350-383. https://doi.org/10.2307/2666999

Forsyth, D. R. (1980). A taxonomy of ethical ideologies. Journal of Personality and Social Psychology, 39, 175-180. https://content.apa.org/doi/10.1037/0022-3514.39.1.175

Forsyth, D. R. (1992). Judging the morality of business practices: The influences of personal moral philosophies. Journal of Business Ethics, 11, 461-470. https://doi.org/10.1007/BF00870557

Fuller, L. (2021a). Foundational leadership theory: The inward and outward approach to examine ethical decision-making. Open Journal of Leadership, 10, 79-94. https://doi.org/10.4236/oj1.2021.102006

Fuller, L. (2021b). Managing peer-to-peer cooperation using knowledge-based trust and encouraging the willingness to share tacit knowledge. Open Journal of Business and Management, 9, 1246-1262. https://doi.org/10.4236/ojbm.2021.93067

George, D., \& Mallery, P. (2018). IBM SPSS Statistics 25 step by step. https://doi.org/10.4324/9781351033909

Homans, G. C. (1974). Social behavior: Its elementary forms (Rev. ed.). Harcourt Brace Jovanovich.

Huo, W. W., Cai, Z. Y., Luo, J. L., Men, C. H., \& Jia, R. Q. (2016). Antecedents and intervention mechanisms: A multi-level study of R\&D teams knowledge-hiding behavior. Journal of Knowledge Management, 20, 880-897. https://doi.org/10.1108/JKM-11-2015-0451

Islam, T., Ahmad, S., Kaleem, A., \& Mahmood, K. (2021). Abusive supervision and knowledge sharing: Moderating roles of Islamic work ethic and learning goal orientation. Management Decision, 59(2), 205-222. https://doi.org/10.1108/MD-08-2019-1069

Jensen, T., \& Sandstrom, J. (2013). In defense of stakeholder pragmatism. Journal of Business Ethics, 114, 225-237. https://doi.org/10.1007/s10551-012-1338-y

Jones, D. A. (2009). A novel approach to business ethics training: Improving moral reasoning in just a few weeks. Journal of Business Ethics, 88, 367-379. https://doi.org/10.1007/s10551-008-9969-8

Jordan, G., Miglič, G., Todorović, I., \& Marič, M. (2017). Psychological empowerment, job satisfaction and organizational commitment among lecturers in higher education: Comparison of six CEE countries. Organizacija, 50, 17-32. https://doi.org/10.1515/orga-2017-0004

Khalid, M., Bashir, S., Abdul, K. K., \& Abbas, N. (2018). When and how abusive supervision leads to knowledge hiding behaviors: An Islamic work ethics perspective. Leadership \& Organization Development Journal, 39(6), 794-806. 
https://doi.org/10.1108/LODJ-05-2017-0140

Khan, M. A. S., Ali, M., Usman, M., Saleem, S., \& Jianguo, D. (2019). Interrelationships between ethical leadership, green psychological climate, and organizational environmental citizenship behavior: The moderating role of gender. Frontiers in Psychology, 10, 1977. https://doi.org/10.3389/fpsyg.2019.01977

Kim, S. L., Lee, S., \& Yun, S. (2016). Abusive supervision, knowledge sharing, and individual factors: A conservation-of-resources perspective. Journal of Managerial Psychology, 31(6), 1106-1120. https://doi.org/10.1108/JMP-05-2015-0169

Koay, K., Sandhu, M., Tjiptono, F., \& Watabe, M. (2020). Understanding employees' knowledge hiding behavior: The moderating role of market culture. Behaviour \& Information Technology.

https://doi.org/10.1080/0144929X.2020.1831073

Ladan, S., Nordin, N. B., \& Belal, H. M. (2017). Does knowledge based psychological ownership matter? Transformational leadership and knowledge hiding: A proposed framework. Journal of Business and Retail Management Research, 11(4), 60-67. https://doi.org/10.24052/JBRMR/V11IS04/DKBPOMTLAKHAPF

Lau, C. L. L. (2010). A step forward: Ethics education matters! Journal of Business Ethics, 92, 565-584. https://doi.org/10.1007/s10551-009-0173-2

Lee, S., Kim, S. L., \& Yun, S. (2018). A moderated mediation model of the relationship between abusive supervision and knowledge sharing. Leadership Quarterly, 29(3), 403-413. https://doi.org/10.1016/j.leaqua.2017.09.001

Lewicki, R. J., \& Bunker, B. B. (1996). Developing and maintaining trust in work relationships. In R. M. Kramer \& T. R. Tyler (Eds.), Trust in organizations: Frontiers of theory and research (pp. 114-139). Sage. https://doi.org/10.4135/9781452243610.n7

Mackey, J. D., Frieder, R. E., Brees, J. R., \& Martinko, M. J. (2017). Abusive supervision: A meta-analysis and empirical review. Journal of Management, 43(6), 1940-1965. https://doi.org/10.1177/0149206315573997

Marcus, B., \& Schuler, H. (2004). Antecedents of counterproductive behavior at work: A general perspective. Journal of Applied Psychology, 89(4), 647-660. https://doi.org/10.1037/0021-9010.89.4.647

McGregor, D. (1960). The human side of enterprise. McGraw-Hill

Men, C., Fong, P. S., Huo, W., Zhong, J., Jia, R., \& Luo, J. (2018). Ethical leadership and knowledge hiding: A moderated mediation model of psychological safety and mastery climate. Journal of Business Ethics, 109, 351-366. https://doi.org/10.1007/s10551-018-4027-7

Ming, X., Bai, X., \& Lin, L. (2020). Kick the cat: A serial crossover effect of supervisors' ego depletion on subordinates' deviant behavior. Frontiers in Psychology, 11, 1-11. https://doi.org/10.3389/fpsyg.2020.01314

Mitchell, M. S., \& Ambrose, M. L. (2007). Abusive supervision and workplace deviance and the moderating effects of negative reciprocity beliefs. Journal of Applied Psychology, 92(4), 1159-1168.

https://doi.org/10.1037/0021-9010.92.4.1159

Offergelt, F., Spörrle, M., Moser, K., \& Shaw, J. D. (2019). Leader-signaled knowledge hiding: Effects on employees' job attitudes and empowerment. Journal of Organizational Behavior, 40(7), 819-833. https://doi.org/10.1002/job.2343

Peng, H. (2013). Why and when do people hide knowledge? Journal of Knowledge Management, 17, 398-415. https://doi.org/10.1108/JKM-12-2012-0380

Peng, H., \& Wei, F. (2018). Trickle-down effects of perceived leader integrity on employee creativity: A moderated mediation model. Journal of Business Ethics, 150, 837-851. https://doi.org/10.1007/s10551-016-3226-3

Schyns, B., \& Schilling, J. (2013). How bad are the effects of bad leaders? A meta-analysis of destructive leadership and its outcomes. Leadership Quarterly, 24(1), 138-158. https://doi.org/10.1016/j.leaqua.2012.09.001

Serenko, A., \& Bontis, N. (2016). Understanding counterproductive knowledge behavior: Antecedents and consequences of intraorganizational knowledge hiding. Journal of Knowledge Management, 20, 1199-1224. https://doi.org/10.1108/JKM-05-2016-0203

Skarlicki, D. P., \& Folger, R. (1997) Retaliation in the workplace: The roles of distributive, procedural, and interactional justice. Journal of Applied Psychology, 82, 434-443. https://doi.org/10.1037/0021-9010.82.3.434

Škerlavaj, M., Connelly, C. E., Cerne, M., \& Dysvik, A. (2018). Tell me if you can: Time pressure, prosocial motivation, perspective-taking, and knowledge hiding. Journal of Knowledge Management, 22(7), 1489-1509.

https://doi.org/10.1108/JKM-05-2017-0179 
Sturm, R. E. (2017). Decreasing unethical decisions: The role of morality-based individual differences. Journal of Business Ethics, 142(1), 37-57. https://doi.org/10.1007/s10551-015-2787-x

Tang, P. M., Bavik, Y. L., Chen, Y. F., \& Tjosvold, D. (2015). Linking ethical leadership to knowledge sharing and knowledge hiding: The mediating role of psychological engagement. IPEDR, 84, 71-76.

Tepper, B. J. (2007). Abusive supervision in work organizations: Review, synthesis, and research agenda. Journal of Management, 33, 261-289. https://doi.org/10.1177\%2F0149206307300812

Usman, M., \& Hameed, A. A. (2017). The effect of ethical leadership on organizational learning: Evidence from a petroleum company. Business and Economic Review, 9(4), 1-22. https://doi.org/10.22547/BER/10.2.2

van den Bos, K., \& Lind, E. A. (2002). Uncertainty management by means of fairness judgments. In M. P. Zanna (Ed.), Advances in experimental social psychology, Vol. 34, pp. 1-60). Academic Press. https://doi.org/10.1016/S0065-2601(02)80003-X

Wang, Y., Han, M. S., Xiang, D., \& Hampson, D. P. (2019). The double-edged effects of perceived knowledge hiding: Empirical evidence from the sales context. Journal of Knowledge Management, 23, 279-296. https://doi.org/10.1108/JKM-04-2018-0245

Winter, S. G. (2013). Habit, deliberation, and action: Strengthening the micro-foundations of routines and capabilities. Academy of Management Perspectives, 27, 120-137. https://doi.org/10.5465/amp.2012.0124

Wu, W. L. \& Lee, Y. C. (2017). Empowering group leaders encourages knowledge sharing: Integrating the social exchange theory and positive organizational behavior perspective. Journal of Knowledge Management, 21(2), 474-491. https://doi.org/10.1108/JKM-08-2016-0318

Wu, W. L., \& Lee, Y. C. (2016). How to make a knowledge-sharing group: A group social capital perspective. Personnel Review, 45(3) 523-538. https://doi.org/10.1108/PR-12-2013-0227

Zhang, Z., Wang, M., \& Shi, J. (2012). Leader-follower congruence in proactive personality and work outcomes: The mediating role of leader-member exchange. Academy of Management Journal, 55(1), 111-130. https://doi.org/10.5465/amj.2009.0865

Zhao, H., \& Xia, Q. (2019). Nurses' negative affective states, moral disengagement, and knowledge hiding: The moderating role of ethical leadership. Journal of Nursing Management, 27, 357-370. https://doi.org/10.1111/jonm.12675

Zhu, W., Newman, A., Miao, Q., \& Hooke, G. (2013). Revisiting the mediating role of trust on transformational leadership effects: Do different types of trust make a difference? Leadership Quarterly, 24, 94-105. https://doi.org/10.1016/j.leaqua.2012.08.004

\section{Copyrights}

Copyright for this article is retained by the author(s), with first publication rights granted to the journal.

This is an open-access article distributed under the terms and conditions of the Creative Commons Attribution license which permits unrestricted use, distribution, and reproduction in any medium, provided the original work is properly cited. 